\title{
Investigation of the antiobesity and antioxidant properties of wild Plumbago europaea and Plumbago auriculata from North Palestine
}

\author{
Nidal Amin Jaradat ${ }^{*}$, Abdel Naser Zaid and Fatima Hussein
}

\begin{abstract}
Background: Historically, plants have proven their value as a source of phytochemicals with therapeutic potentials and recently they play an important role in the discovery of novel drugs.

Objectives: The current study aimed to investigate new antiobesity drugs from Plumbago europaea and Plumbago auriculata through the inhibition of the adsorption of dietary lipids. In vitro porcine pancreatic lipase inhibitory tests were conducted with weight reduction property as well as this study aimed to explore the antioxidant potential and to estimate total phenolic, flavonoid, and tannin contents in both of the studied species.

Methods: Antioxidant capacity was evaluated using ferric reducing antioxidant power and DPPH assays, and porcine pancreatic lipase inhibitory tests were conducted using the UV spectrophotometric method, while total flavonoid, phenol, and tannin contents were estimated using standard phytochemical analytical methods.

Results: Antioxidant potential and total flavonoid, phenol, and tannin contents of P. europaea were significantly higher than those of $P$. auriculata, and both of the studied species have potential antiobesity activity in comparison with orlistat.

Conclusion: Results of the present study show that both of the studied Plumbago species consist of bioactive compounds that can act as lipase inhibitors and therefore can be useful for the development of functional foods against obesity. It can also be used as a source of lead compounds for designing new antiobesity drugs. Further isolation, identification, and characterization of phyto-active compounds responsible for antiobesity action are required to evaluate the full therapeutic potentials of these plants.
\end{abstract}

Keywords: Anti-lipase, Antioxidant, Flavonoids, Plumbago europaea, Plumbago auriculata

\section{Background}

For millennia, the plant kingdom has been a valuable source of therapeutic agents and till now many modern drugs are semi-synthesized or isolated from these natural sources [1].

In the past decades, the major focus of pharmaceutical companies was mainly on synthetic molecules as a source of drug discovery due to their effectiveness, ease

*Correspondence: nidaljaradat@najah.edu

Department of Pharmacy, Faculty of Medicine and Health Sciences,

An-Najah National University, P. O. Box 7, Nablus, Palestine of production, and supply. For all these reasons, synthetic medications spread globally, while drug discovery from natural sources was associated with some intrinsic difficulties, and the pharmaceutical industry has shifted its main focus to synthetic molecules [2-4]. Unfortunately, many side effects and adverse reactions were associated with these synthetic drugs, and the world has witnessed an increase in the use of plants to treat diseases and to promote better health $[5,6]$.

One of the most important challenges that are still facing humanity is weight gain and obesity. This problem is drawing the attention of both the cosmetic and the 
pharmaceutical industries. In fact, many countries consider a slim body as a factor of beauty. In addition, obesity is currently considered a worrying epidemic disorder. In fact, it touches adults, as well as children and teenagers. It was estimated that about 300,000 people die each year from obesity and related causes, which puts this disorder as the second leading cause of death. In fact, being both overweight and obese increases the risk of several diseases and health conditions such as high triglycerides, cholesterol, diabetes, heart disease, high blood pressure, tumors (breast, colon, and endometrial), sleep disorders, and respiratory problems [7-9].

Previous studies showed that some medicinal plants contain mixtures of antioxidant phytochemical compounds such as flavonoids, tannins, and polyphenols that can inhibit or reduce oxidative deterioration of lipids, proteins, and DNA, consequently preventing neurodegenerative diseases, radiation damage, atherosclerosis, chronic inflammatory diseases, carcinogenesis, arthritis, aging, liver injury, and other pathological disorders [10-12].

Both of the studied plants species Plumbago europaea and Plumbago auriculata (Fig. 1) belonged to the Plumbaginaceae family. Plumbago europaea L., also known as the common leadwort, is a perennial plant which is native to the Central Asia and Mediterranean regions. The plant is well known to contain europetin flavonol and plumbagin naphthoquinones [13-15]. The P. europaea plant is used for the treatment of respiratory disorders, hepatitis, edema, leprosy, inflammations, scabies, toothache, warts, blisters, injury, calluses, and skin hardness in traditional Palestinian, Jordanian, Italian, and Turkish folkloric ethno-medicines [16-22].

Plumbago auriculata Lam. (Cape Leadwort) is a species of the perennial flowering plants which are found in South Africa, subtropical gardens in Florida, and in all the warm winter climate regions across the world [23]. In South African and Arabian folk medicines, P. auriculata is used for the treatment of malaria, wounds, gastroesophageal reflux disease, broken bones, and to remove warts [24-27]. Sitosterol steroids, plumbagin naphthoquinones, epi-isoshinanolone, 3-O-glucosylsitosterol, palmitic acid, and plumbagic acid were isolated from $P$. auriculata [24].

The current study aimed to investigate new antiobesity drugs from the leaves of $P$. europaea and $P$. auriculata through the inhibition of the adsorption of dietary lipids. In vitro porcine pancreatic lipase inhibitory with weightreducing properties were conducted for this purpose. In addition, this study aimed to explore the antioxidant potential and to estimate total phenolic, flavonoid, and tannin contents in both of the studied Plumbago species.

To the best of our knowledge, all the evaluated plants in this study have not been screened before, either for their antiobesity activity or for their total tannin, flavonoid, and phenol contents.

\section{Methods \\ Instrumentation}

Shaker device (Memmert shaking incubator, Germany), rotary evaporator (Heidolph OB2000 Heidolph VV2000, Germany), UV-visible spectrophotometer (Jenway 7135, England), grinder (Moulinex model, Uno, China), and balance (Rad wag, AS 220/c/2, Poland) were used in this study.

\section{Chemicals and reagents}

Methanol (Loba Chemie, India), acetone (Alzahraa, Palestine), Millon's reagent (Gadot, Israel), ninhydrin solution (Alfa Agar, England), Benedict's reagent (Gadot, Israel), Molisch's reagent, $\mathrm{H}_{2} \mathrm{SO}_{4}$, iodine solution (AlfaAesar, England), $\mathrm{NaOH}$ (Gadot, Israel), chloroform, $\mathrm{HCl}$ (Sigma-Aldrich, Germany), magnesium ribbon, acetic acid (Frutarom Ltd., Israel), $\mathrm{FeCl}_{3}$ (Riedel-de-haen, Germany), Folin-Ciocalteu reagent (Sigma-Aldrich, Germany), $\mathrm{NaHCO}_{3}$ (Merck, Germany), trichloroacetic acid (Sigma-Aldrich, Germany), (s)-(-)-6-hydroxy-2,5,7,8-tetramethylchroman-2 carboxylic acid (Trolox) (Sigma-Aldrich, Denmark), 2,2-diphenyl1-picrylhydrazyl (DPPH) (Sigma-Aldrich, Germany), dimethyl sulfoxide (DMSO) (Riedel-de-haen, Germany), acetonitrile (Sigma-Aldrich, Germany), porcine pancreatic lipase type II (Sigma, USA), $p$-nitrophenol (PNP) (Sigma-Aldrich, Germany), orlistat, quercetin (Sigma, USA), gallic acid, $\mathrm{AlCl}_{3}$, sodium nitrite, vanillin, catechin (Sigma- Aldrich, Germany), and potassium ferricyanide (Riedel-de-haen, Germany) were used in this study.

\section{Plant materials}

The leaves of $P$. europaea and $P$. auriculata were collected in June, 2015 from the Jericho and Tubas regions of Palestine. Botanical identification was carried out in the Pharmacognosy and Herbal Products Laboratory at An-Najah National University by the Pharmacognosist Dr. Nidal Jaradat, and the voucher specimen codes were Pharm-PCT-1899 and Pharm-PCT-1900, respectively.

The leaves were washed and then dried in the shade at room temperature until all the plant parts became well dried. After drying, the plant materials were ground well into a fine powder using a mechanical blender and transferred into airtight containers with proper labeling for future use.

\section{Preparation of different extracts of plants}

About $10 \mathrm{~g}$ of the grounded leaves of P. europaea and $P$. auriculata plants were soaked separately in 11 of three 
different solvents (water, methanol, and acetone), and each of the extracts was placed in a shaker device at 100 rounds per minute for $72 \mathrm{~h}$ at room temperature and then stored in a refrigerator for 4 days. After that, the extract was filtered using Whatman filter paper No. 1 and concentrated under vacuum on a rotary evaporator at $35{ }^{\circ} \mathrm{C}$. The crude extracts were then stored at $4{ }^{\circ} \mathrm{C}$ in the refrigerator for further use [28].

\section{Qualitative phytochemical analysis}

Qualitative preliminary phytochemical screening of primary and secondary metabolic compounds such as starch, phenols, cardiac glycosides, flavonoids, saponin glycosides, alkaloids, steroids, volatile oils, and tannins was carried out according to the standard common phytochemical methods described by Trease and Evans [29] and Harborne [30].

\section{Screening of antioxidant activity Ferric reducing assay}

Methanolic extracts were subjected to this assay by preparing methanolic solutions of different concentrations $(100,200,300,400$, and $500 \mu \mathrm{g} / \mathrm{ml})$, and $1 \mathrm{ml}$ from each dilution was mixed with $2.5 \mathrm{ml}$ of phosphate buffer (200 mM, pH 6.6) and $2.5 \mathrm{ml}$ of $1 \%$ potassium ferricyanide in a separate tube.

The tubes were placed in a boiling water bath for $20 \mathrm{~min}$ at $50{ }^{\circ} \mathrm{C}$, cooled rapidly, and then mixed with $2.5 \mathrm{ml}$ of $10 \%$ trichloroacetic acid and $0.5 \mathrm{ml}$ of $0.1 \%$ ferric chloride. The amount of iron (II)-ferricyanide complex formed was determined by measuring the formation of Perl's Prussian blue at $700 \mathrm{~nm}$ after $10 \mathrm{~min}$, and the presence of antioxidants (reductants) in the sample would result in the reduction of $\mathrm{Fe}^{3+}$ to $\mathrm{Fe}^{2+}$ by donating an electron. The amount of $\mathrm{Fe}^{2+}$ complex formed by the reduction of $\mathrm{Fe}^{3+}$ can be monitored by measuring the formation of color complex at $700 \mathrm{~nm}$. An increase in absorbance indicates an increase in reduction ability. The reducing capacity of the compound may serve as a significant indicator of its potential antioxidant activity. This would have the effect of converting free radicals to more stable products and thus terminating free radicalinitiated chain reactions [31].

\section{DPPH assay}

A stock solution of a concentration of $1 \mathrm{mg} / \mathrm{ml}$ in methanol was firstly prepared for the plant extract and Trolox. The working solutions of different concentrations $(1,2,3$, $5,7,10,20,30,40,50,80$, and $100 \mu \mathrm{g} / \mathrm{ml}$ ) were prepared by serial dilution of the stock solution with methanol. DPPH was freshly prepared at a concentration of $0.002 \%$ w/v. The DPPH solution was mixed with methanol and the above-prepared working concentration in a ratio of
1:1:1, respectively. The spectrophotometer was zeroed using methanol as a blank solution. The first solution of the series concentration was DPPH with methanol only. The solutions were incubated in the dark for $30 \mathrm{~min}$ at room temperature before the absorbance readings were recorded at $517 \mathrm{~nm}$ [32]. The percentage of antioxidant activity of the plants and the Trolox standard were calculated using the following formula:

$$
\begin{aligned}
& \text { Percentage of inhibition of DPPH activity (\%) } \\
& \quad=(A-B) / A \times 100 \%,
\end{aligned}
$$

where $A$ is the optical density of the blank and $B$ is the optical density of the sample.

The antioxidant half maximal inhibitory concentration $\left(\mathrm{IC}_{50}\right)$ for the plant samples and the standard were calculated using BioDataFit edition 1.02 (data fit for biologist).

\section{Pancreatic lipase inhibition \\ Preparation of lipase stock solution and plant extract dilution series}

The porcine pancreatic lipase inhibitory assay was adapted from Zheng et al. [33] and Bustanji et al. [34] with some modifications. From the prepared $1 \mathrm{mg} / \mathrm{ml}$ plant extract stock solution in 10\% DMSO, solutions of five different concentrations $(200,400,600,800$, and $1000 \mu \mathrm{g} / \mathrm{ml}$ ) were prepared, while $1 \mathrm{mg} / \mathrm{ml}$ stock solution of pancreatic lipase enzyme was prepared immediately before use, which was suspended in Tris- $\mathrm{HCl}$ buffer.

\section{Preparation of lipase substrate stock solution}

The stock solution of PNPB ( $p$-nitrophenyl butyrate) was prepared by dissolving $20.9 \mathrm{mg}$ of PNPB in $2 \mathrm{ml}$ of acetonitrile. For each working test tube, $0.1 \mathrm{ml}$ of porcine pancreatic lipase $(1 \mathrm{mg} / \mathrm{ml})$ was added to a test tube containing $0.2 \mathrm{ml}$ plant extract from each diluted solution series for each studied plant. The resulting mixture was then made up to $1 \mathrm{ml}$ by adding Tris$\mathrm{HCL}$ solution and incubated at $37{ }^{\circ} \mathrm{C}$ for $15 \mathrm{~min}$. After the incubation period, $0.1 \mathrm{ml}$ of PNPB ( $p$-nitrophenyl butyrate) solution was added to each test tube. The mixture was again incubated for $30 \mathrm{~min}$ at $37^{\circ} \mathrm{C}$. Pancreatic lipase activity was determined by measuring the hydrolysis of $p$-nitrophenolate to $p$-nitrophenol at $405 \mathrm{~nm}$ using a spectrophotometer. The same procedure was repeated for Orlistat which was used as a reference compound [35].

\section{Determination of total tannin content in the different extracts}

Total tannin content (proanthocyanidins) was determined according to the method of Sun et al. [36], with 
some modification. To $0.5 \mathrm{ml}$ of each of the diluted catechin solutions of different concentrations $(0.1,0.4,0.5$, 0.7 , and $1 \mathrm{mg} / \mathrm{ml}$ ), $3 \mathrm{ml}$ of $4 \%$ vanillin solution in methanol and $1.5 \mathrm{ml}$ of concentrated $\mathrm{HCl}$ were added. The mixture was allowed to stand for $15 \mathrm{~min}$, and absorption was measured at $500 \mathrm{~nm}$ against methanol as a blank. The amount of total tannins is expressed as $\mathrm{mg}$ $(+)$-catechin/g plant extract (mg CAE/g). All samples were analyzed in triplicate. The same procedure was repeated for methanolic extracts of the two plants [36].

\section{Determination of total phenolic content}

Total phenolic content in the plant methanolic extract was determined using spectrophotometric method with some modifications [37]. $1 \mathrm{mg} / \mathrm{ml}$ stock aqueous solutions of methanolic extracts were prepared. The reaction mixture was prepared by mixing $0.5 \mathrm{ml}$ of plant extract solution, $2.5 \mathrm{ml}$ of $10 \%$ Folin-Ciocalteu reagent dissolved in water, and $2.5 \mathrm{ml}$ of $7.5 \%$ of $\mathrm{NaHCO}_{3}$ aqueous solution. The samples were incubated in a thermostat at $45^{\circ} \mathrm{C}$ for $45 \mathrm{~min}$. The absorbance was determined using a spectrophotometer at the wavelength of $765 \mathrm{~nm}$. The samples were prepared in triplicate for each analysis and the mean value of absorbance was calculated. The same procedure was repeated for the standard solution of gallic acid and the calibration line was construed. Based on the measured absorbance, the concentration was expressed in terms of gallic acid equivalent (mg of GAE/g of extract), and this procedure was repeated three times for both of the studied Plumbago species.

\section{Determination of total flavonoid content}

Total flavonoid content was measured with the aluminum chloride colorimetric assay [38]. $10 \mathrm{mg}$ of quercetin was dissolved in $100 \mathrm{ml}$ of methanol and then diluted to 10 , $30,50,70$, and $100 \mu \mathrm{g} / \mathrm{ml}$ using methanol. The stock solution of plant extract was prepared by dissolving $100 \mathrm{mg}$ of the methanolic extract in $5 \mathrm{ml}$ methanol and transferred to a $10-\mathrm{ml}$ volumetric flask and made up to the volume with methanol. $0.3 \mathrm{ml}$ of $5 \%$ sodium nitrite solution was added into each working test tube. After $5 \mathrm{~min}, 0.3 \mathrm{ml}$ of $10 \%$ aluminum chloride was added. At the 6th minute, $2 \mathrm{ml}$ of $1 \mathrm{M}$ sodium hydroxide was added. Finally, the volume was made up to $10 \mathrm{ml}$ with distilled water and mixed well. The absorbance was measured at $510 \mathrm{~nm}$ using a UV-visible spectrophotometer. A blank test was performed using distilled water. Quercetin was used as the standard. The samples were analyzed in triplicate. The calibration curve was plotted using standard quercetin. The total flavonoid content of the extract was expressed as $\mathrm{mg}$ of quercetin equivalents/g ( $\mathrm{mg}$ of QUE/g) of plant extract, and this procedure was repeated three times for both of the studied plants species.

\section{Results}

Phytochemical screening

Qualitative phytochemical screening examinations of $P$. europaea and P. auriculata showed that the aqueous and organic (acetone, methanolic) extracts contain the same phytochemical classes such as cardiac glycosides, alkaloids, starch, phenols, tannins, phytosteroids, flavonoids, and volatile oils as presented in Table 1.

\section{Total tannin content}

A standard calibration curve (Fig. 2) was established to calculate the percentage of tannins in the methanolic extracts of $P$. europaea and $P$. auriculata, using the following equation:

$$
Y=0.9554 X+0.0003, \quad R^{2}=0.9988,
$$

where $Y$ is the absorbance at $500 \mathrm{~nm}$ and $X$ is the total tannin content in the plant methanolic extract.

The total tannin content according to the standard calibration curve equation shown in Fig. 1 was $29.58 \pm 0.24 \mathrm{mg}$ CAE/g for $P$. europaea methanolic extract, while that for $P$. auriculata was $9.55 \pm 0.2 \mathrm{mg} \mathrm{CAE} / \mathrm{g}$ (Fig. 2).

\section{Total phenolic content}

Estimation of total phenolic content was carried out according to the standard calibration curve (Fig. 3) and the results were expressed as $\mathrm{mg} / \mathrm{g}$ gallic acid equivalent using the standard calibration curve equation:

$$
Y=7.515 X+0.0308, \quad R^{2}=0.9927,
$$

where $Y$ is the absorbance at $765 \mathrm{~nm}$ and $X$ is the total phenolic content in the plant extract.

The total phenolic content in P. europaea methanolic extract was $41.5 \pm 0.58 \mathrm{mg}$ GAE/g of plant extract, which is a relatively high percentage of phenolic content, while in $P$. auriculata the total phenolic content was $24.3 \pm 0.45 \mathrm{mg}$ GAE/g plant extract which is relatively low in comparison with the methanolic extract of P. europaea.

\section{Total flavonoid content}

A standard calibration curve was prepared to calculate the percentage of flavonoid content using the following equation:

$$
Y=0.0003 X+0.00016, \quad R^{2}=0.9966,
$$

where $Y$ is the absorbance at $410 \mathrm{~nm}$ and $X$ is the total flavonoid content in the plant methanolic extract, as presented in Fig. 4.

From the standard calibration curve shown in Fig. 3, the total flavonoid content in the methanolic extract of P. europaea was $94.66 \pm 0.94 \mathrm{mg}$ QUE/g of plant extract which is considered a relatively high percentage of 
Table 1 Phytochemical classes identified in the aqueous, acetone, and methanolic extracts of both plumbago studied species

\begin{tabular}{|c|c|c|c|c|c|c|}
\hline \multirow[t]{2}{*}{ Phytochemical classes } & \multicolumn{2}{|c|}{ Aqueous extract } & \multicolumn{2}{|c|}{ Methanolic extract } & \multicolumn{2}{|c|}{ Acetone extract } \\
\hline & P. europaea & P. auriculata & P. europaea & P. auriculata & P. europaea & P. auriculata \\
\hline Cardiac glycosides & ++ & + & ++ & + & +++ & ++ \\
\hline Saponin glycosides & - & - & - & - & - & - \\
\hline Alkaloids & - & - & - & - & - & - \\
\hline Starch & +++ & ++ & - & - & - & - \\
\hline Phenols & ++ & + & ++ & + & ++ & + \\
\hline Volatile oil & + & + & + & + & + & + \\
\hline Tannin & + & + & ++ & + & ++ & + \\
\hline Phytosteroids & ++ & + & +++ & ++ & +++ & ++ \\
\hline Flavonoids & ++ & + & +++ & ++ & +++ & ++ \\
\hline
\end{tabular}

$(-)$ means the absence of the content, $(+)$ means low content, $(++)$ means mild content, and $(+++)$ means high content
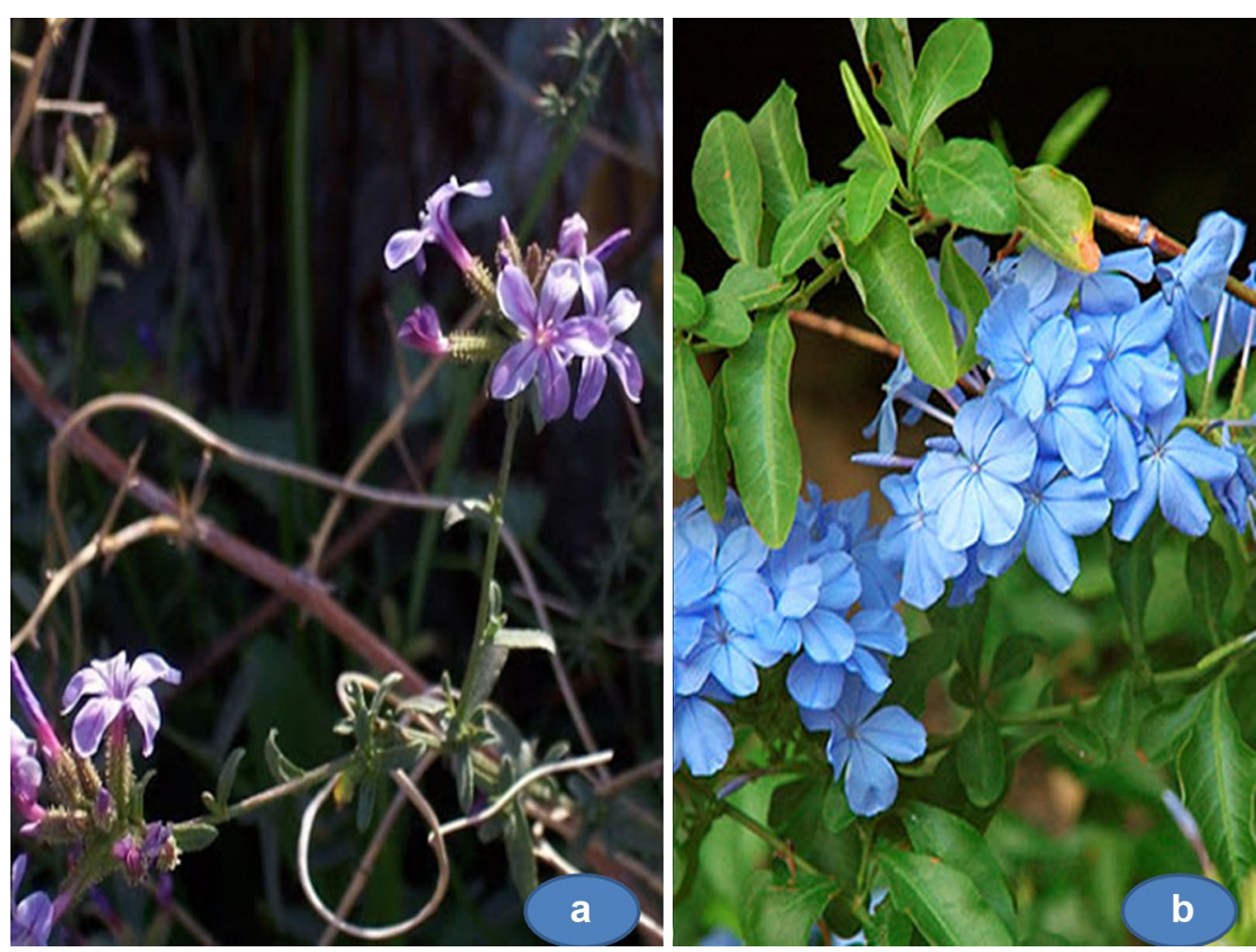

Fig. 1 The studied Plumbago plant species, where a represents Plumbago europaea and $\mathbf{b}$ represents Plumbago auriculata

flavonoid content. On the other hand, the total flavonoid content in the methanolic extract of $P$. auriculata was $87.12 \pm 0.5 \mathrm{mg}$ QUE/g of plant extract.

All the previous results of total phenolic, flavonoid, and tannin contents of methanolic extract for both Plumbago plant species are listed and explained in Table 2 and Fig. 5.

\section{Antioxidant screening assay}

$\mathrm{IC}_{50}$ values for $P$. europaea and $P$. auriculata were 21.38 and $89.12 \mu \mathrm{g} / \mathrm{ml}$, respectively, while that for Trolox was $1.85 \mu \mathrm{g} / \mathrm{ml}$ (Fig. 6). This indicates the high potential for free radical scavenging of $P$. europaea versus $P$. auriculata. The antioxidant can donate an electron to free radicals, which leads to neutralization of the radicals. 


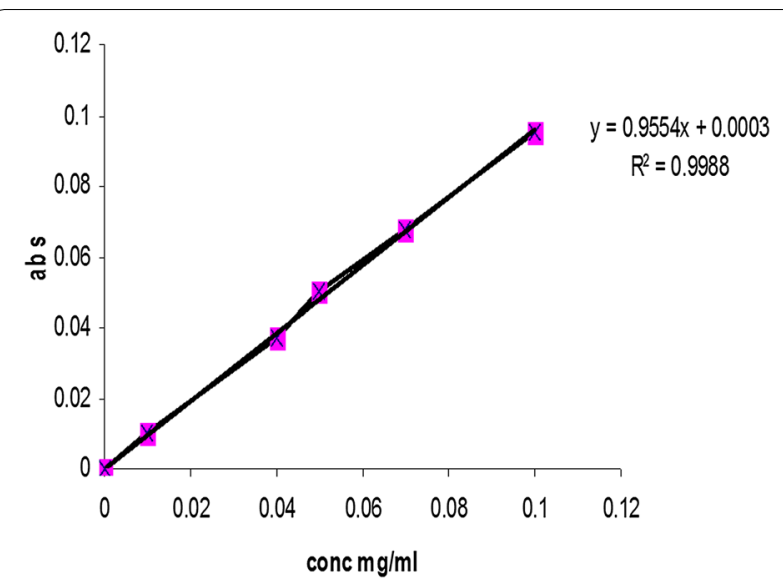

Fig. 2 Standard calibration curve for catechin measured at $500 \mathrm{~nm}$ wavelength

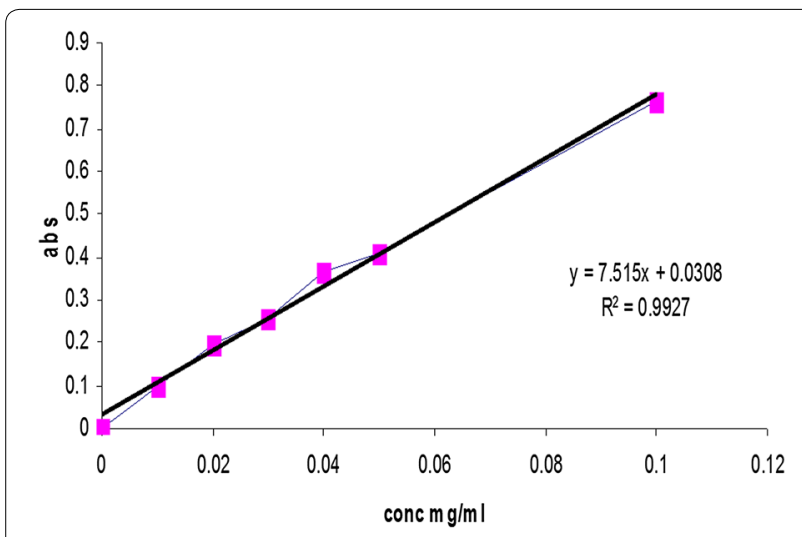

Fig. 3 Standard calibration curve for gallic acid measured at 765 nm wavelength

Reducing power was measured by direct electron donation in the reduction of $\mathrm{Fe}^{3+}\left(\mathrm{CN}^{-}\right)^{6}-\mathrm{Fe}^{2+}\left(\mathrm{CN}^{-}\right)^{6}$ (Fig. 7). The product was visualized by forming the intense Prussian blue color complex and then the absorbance was measured at the $\lambda$ value of $700 \mathrm{~nm}$. As shown in Fig. 6, a higher absorbance value indicates a stronger reducing power of the samples.

Using ferric reducing power assay, $\mathrm{IC}_{50}$ value for the methanolic extract of $P$. europaea was $69.18 \mu \mathrm{g} /$ $\mathrm{ml}$ and that for the methanolic extract of $P$. auriculata was $70.79 \mu \mathrm{g} / \mathrm{ml}$, whereas the $\mathrm{IC}_{50}$ value for Trolox was
$50.12 \mu \mathrm{g} / \mathrm{ml}$. This result indicates the relatively high ferric reducing activity of these two extracts compared to pure standard Trolox.

\section{Pancreatic lipase enzyme inhibition activity}

The methanol extracts anti-lipase $\mathrm{IC}_{50}$ value of $P$. europaea and $P$. auriculata was 134.29 and $130.32 \mu \mathrm{g} / \mathrm{ml}$, respectively, as shown in Fig. 8. This result showed that both the studied Plumbago species possess relatively the same inhibitory action against lipase enzyme.

The orlistat reference standard compound showed a very high percentage of inhibition against pancreatic lipase enzyme with an $\mathrm{IC}_{50}$ value of $29.9 \mu \mathrm{g} / \mathrm{ml}$, while the extracts of $P$. europaea and $P$. auriculata showed relatively moderate lipase inhibition compared with orlistat (Fig. 8).

\section{Discussion}

Recently, the focus on medicinal plants research has increased considerably, especially for those plants that were used in folk medicines. This increasing interest is due to the scarcity of therapeutic agents available to treat chronic diseases, increasing of bacterial resistance and the harmful side effects of chemical compounds [39, 40]. Natural plant products containing polyphenolic compounds such as phenolic acids, tannins, anthocyanins, and flavonoids were demonstrated to have potential health benefits for the treatment of metabolic disorders such as diabetes mellitus, hypercholesterolemia, overweight, and obesity [41]. Several studies were conducted on natural products in order to assess their pharmacological activities including antioxidant and anti-lipase effects [42-44].

Therefore, the consumption of flavonoids in food and other supplements has been advised to reduce weight gain and obesity [45-47].

In this context, $P$. europaea and $P$. auriculata exhibited high flavonoid contents of $94.66 \mathrm{mg}$ QUE/g and $87.12 \mathrm{mg}$ QUE/g, respectively, which may explain their anti-lipase activity.

In addition, $P$. europaea and $P$. auriculata showed a promising antioxidant activity in both of the utilized DPPH and ferric reducing assays.

On the other hand, total phenolic content was higher in P. europaea, which was $41.5 \mathrm{mg} \mathrm{GAE} / \mathrm{g}$, while in

Table 2 Total phenolic, flavonoid, and tannin contents of methanolic extracts for $P$. auriculata and $P$. europaea

\begin{tabular}{lll}
\hline $\begin{array}{l}\text { Studied species of Plumbago } \\
\text { plants }\end{array}$ & $\begin{array}{l}\text { Total phenolic content (mg } \\
\text { GAE/g) } \pm \text { SD }\end{array}$ & $\begin{array}{l}\text { Total flavonoid content (mg } \\
\text { QUE/g) } \pm \text { SD }\end{array}$ \\
\hline $\begin{array}{ll}\text { P. auriculata } \\
\text { P. europaea }\end{array}$ & $24.3 \pm 0.22$ & $87.12 \pm 0.15$ \\
\hline
\end{tabular}




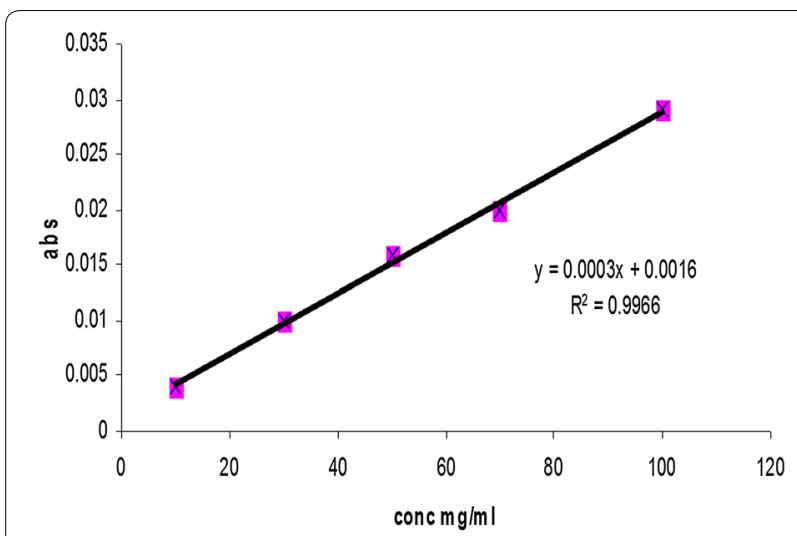

Fig. 4 Standard calibration curve for quercetin measured at $410 \mathrm{~nm}$ wavelength

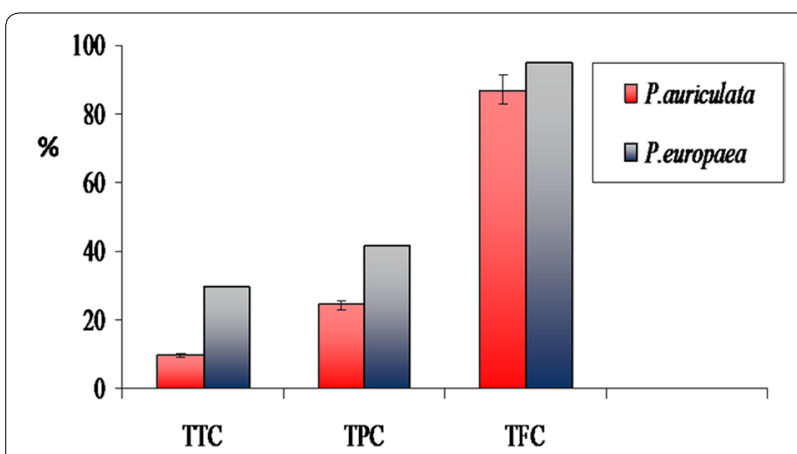

Fig. 5 Total phenolic content (TPC), total flavonoid content (TFC), and total tannin content (TTC) of the methanolic extracts of $P$. auriculata and P. europaea plants

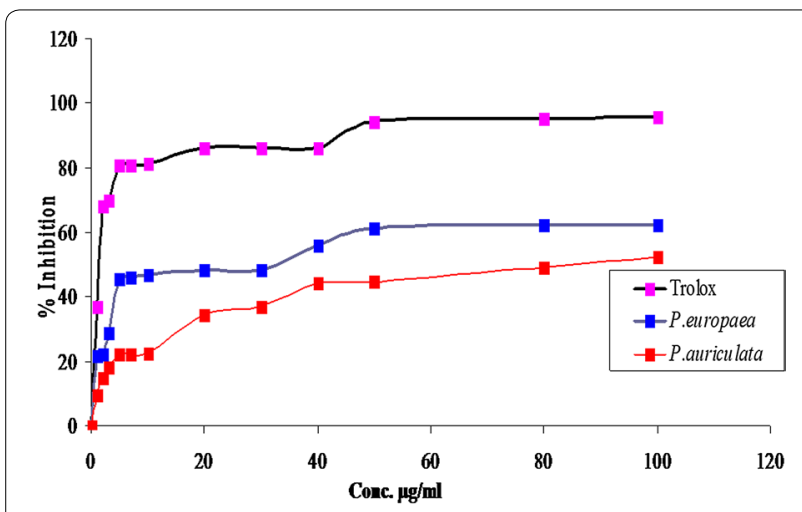

Fig. 6 DPPH free radical scavenging curve for the methanolic extracts of P. europaea and P. auriculata and Trolox

P. auriculata the total phenolic content was $24.3 \mathrm{mg}$ GAE/g. At the same time, the total tannin content was also higher in $P$. europaea than in $P$. auriculata, which were $29.58 \mathrm{mg} \mathrm{CAE} / \mathrm{g}$ and $9.55 \mathrm{mg} \mathrm{CAE} / \mathrm{g}$, respectively.

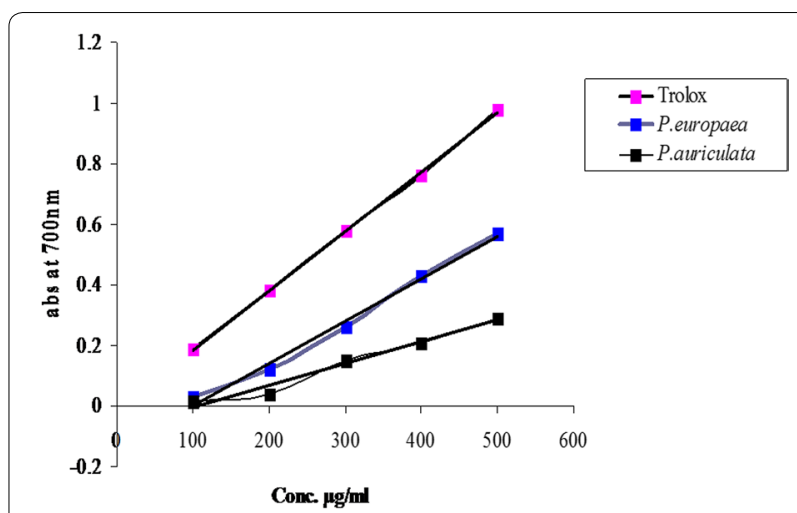

Fig. 7 Ferric reducing power assay using the methanolic extracts of P. europaea and P. auriculata and Trolox

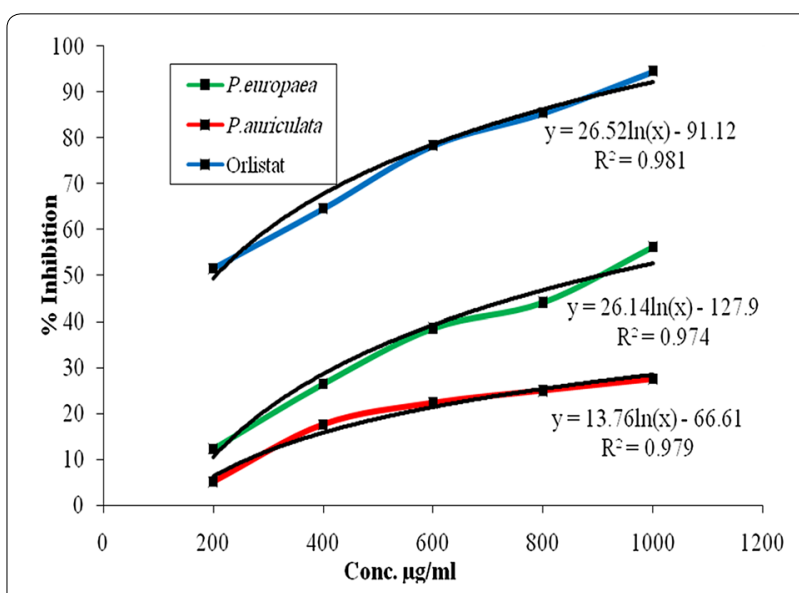

Fig. 8 Pancreatic lipase inhibition activity of the methanolic extracts of P. europaea and P. auriculata in comparison with orlistat

In another investigation conducted by Amoo et al. [48] in South Africa, the total phenolic and flavonoid contents in P. auriculata were $15.0 \mathrm{mg} \mathrm{GAE} / \mathrm{g}$ and $5.5 \mathrm{mg}$ QUE/g, respectively. This means that wild-growing $P$. auriculata used in our study had much better total phenolic and flavonoid contents than South African P. auriculata [48].

Using ferric reducing power assay, the $\mathrm{IC}_{50}$ values were 69.18 and $70.79 \mu \mathrm{g} / \mathrm{ml}$ for the methanolic extracts of $P$. europaea and $P$. auriculata, respectively, whereas the $\mathrm{IC}_{50}$ value for Trolox was $50.12 \mu \mathrm{g} / \mathrm{ml}$. This result indicates the relatively high ferric reducing activity of these two extracts compared to Trolox.

Moreover, using $\mathrm{DPPH}$ assay the $\mathrm{IC}_{50}$ values for $P$. europaea and $P$. auriculata were 21.38 and $89.12 \mu \mathrm{g} / \mathrm{ml}$, respectively, while the $\mathrm{IC}_{50}$ value for Trolox was $1.85 \mu \mathrm{g} /$ $\mathrm{ml}$. This indicates the high potential antioxidant activity of $P$. europaea versus $P$. auriculata.

Moreover, there was a significant linear correlation between the antioxidant activity determined using the 
DPPH and ferric reducing assays and the total phenolic, tannin, and flavonoid contents in both of the studied Plumbago species. However, no significant relationship was observed between the antioxidant activity and the total tannin, phenolic, and flavonoid contents in both of the studied Plumbago species and the anti-lipase activity because both of the studied species had almost the same potential as anti-lipase drugs.

A study conducted by Bircan and Kirbag [49] evaluated the antioxidant activity of $P$. europaea growing in Turkey using DPPH assay and found that it was $83.62 \mu \mathrm{g} /$ $\mathrm{ml}$, while in the studied P. europaea growing in Palestine it was $21.38 \mu \mathrm{g} / \mathrm{ml}$ which exhibited an antioxidant activity four times better than that of the Turkish P. europaea [49]. In fact, the impact of the flavonoid content on antiaging and anti-lipase activities was documented.

On the other hand, both of the studied species had more powerful antioxidant activity than Plumbago zeylanica that had an antioxidant activity of $88.45 \mu \mathrm{g} / \mathrm{ml}$ which was studied by Sini et al. [50] and which is almost equal to the antioxidant activity of $P$. auriculata which was $89.12 \mu \mathrm{g} / \mathrm{ml}$.

In fact, overweight and obesity have become epidemics and are increasing at an alarming rate in both the developed and developing countries [51, 52]. Pancreatic lipase is considered the principal lipolytic enzyme which plays an essential role in the efficient digestion of lipids and is responsible for the hydrolysis of about $70 \%$ of total ingested fats [53].

The $\mathrm{IC}_{50}$ value showed potent inhibitory action against lipase enzyme when comparing with Arum palaestinum which was previously reported by Bustanji et al. [54] to have potent lipase inhibitory action with an $\mathrm{IC}_{50}$ value of $107.7 \mu \mathrm{g} / \mathrm{ml}$.

For the studied Plumbago plant species, the potential activity against pancreatic lipase enzyme can be attributed to the high content of flavonoids which are well known to exhibit potential activity against pancreas and liver enzymes.

\section{Conclusion}

In the present study, the total contents of phytochemical compounds including flavonoids, phenols, and tannins as well as their antioxidant and antiobesity activities of the two species, P. europaea and P. auriculata, were evaluated and compared. The obtained results suggested that these plants have moderate to potent antioxidant activity and both of them had high contents of flavonoids. In addition, they could be used as a source of lead drugs for developing new antiobesity agents. However, further isolation, identification, and characterization of phyto-active compounds responsible for anti-lipase action are required to evaluate the full therapeutic potentials of these plants.
Authors' contributions

All research has been done by the authors. All authors read and approved the final manuscript.

\section{Acknowledgements}

The authors acknowledge the assistance of the technicians Mohamad Arar and Linda Esa, and a special thanks to Jonathan Wright (English Center-AnNajah National University) for English language editing and proofing.

\section{Competing interests}

The authors declare that they have no competing interests.

Received: 21 October 2016 Accepted: 17 November 2016

Published online: 02 December 2016

\section{References}

1. Rischer H, Hakkinen ST, Ritala A, Seppanen-Laakso T, Miralpeix B, Capell T, et al. Plant cells as pharmaceutical factories. Curr Pharm Des. 2013;19(31):5640-60.

2. Kinghorn $A D$, Pan L, Fletcher $\mathrm{JN}$, Chai $\mathrm{H}$. The relevance of higher plants in lead compound discovery programs. J Nat Prod. 2011;74(6):1539-55.

3. Newman DJ, Cragg GM. Natural products as sources of new drugs over the 30 years from 1981 to 2010. J Nat Prod. 2012;75(3):311-35.

4. David B, Wolfender J-L, Dias DA. The pharmaceutical industry and natural products: historical status and new trends. Phytochem Rev. 2015;14(2):299-315.

5. Schuster $D$, Laggner $C$, Langer $T$. Why drugs fail-a study on side effects in new chemical entities. Curr Pharm Des. 2005;11(27):3545-59.

6. Alqahtani S, Mohamed LA, Kaddoumi A. Experimental models for predicting drug absorption and metabolism. Expert Opinion Drug Metab Toxicol. 2013:9(10):1241-54.

7. Hopkins M, Finlayson G, Duarte C. Modelling the associations between fat-free mass, resting metabolic rate and energy intake in the context of total energy balance. Int J Obes. 2016;40(2):312-8.

8. Kusminski CM, Bickel PE, Scherer PE. Targeting adipose tissue in the treatment of obesity-associated diabetes. Nat Rev Drug Discov. 2016:3:1033-8.

9. Baillie-Hamilton PF. Chemical toxins: a hypothesis to explain the global obesity epidemic. J Altern Complement Med. 2002;8(2):185-92.

10. Turati F, Rossi M, Pelucchi C, Levi F, La Vecchia C. Fruit and vegetables and cancer risk: a review of southern European studies. Br J Nutr. 2015;113(S2):102-10.

11. Kaefer CM, Milner JA. The role of herbs and spices in cancer prevention. J Nutr Biochem. 2008:19(6):347-61.

12. Karbach $S$, Wenzel P, Waisman A, Munzel T, Daiber A. eNOS uncoupling in cardiovascular diseases-the role of oxidative stress and inflammation. Curr Pharm Des. 2014;20(22):3579-94.

13. Iwashina T. Flavonoid properties of five Families newly incorporated into the Order Caryophyllales (Review). Bull Natl Sci Mus Ser B. 2013:39(1):25-51

14. Al-Nuri MA, Hannoun MA, Zatar NA, Abu-Eid MA, Al-Jondi WJ, Hussein $\mathrm{Al}$, et al. Plumbagin, a naturally occurring naphthoquinone: its isolation, spectrophotometric determination in roots, stems, and leaves in Plumbago europaea L. Spectrosc Lett. 1994;27(4):409-16.

15. Muhammad HM, Saour KY, Naqishbandi AM. Quantitative and qualitative analysis of Plumbagin in the leaf and root of Plumbago europaea growing naturally in Kurdistan by HPLC. Iraqi J Pharm Sci. 2009; 18:54-60.

16. Sezik E, Yeşilada E, Honda G, Takaishi Y, Takeda Y, Tanaka T. Traditional medicine in Turkey X. Folk medicine in central Anatolia. J Ethnopharmacol. 2001;75(2):95-115.

17. Jaradat NA, Al-Ramahi R, Zaid AN, Ayesh OI, Eid AM. Ethnopharmacological survey of herbal remedies used for treatment of various types of cancer and their methods of preparations in the West Bank-Palestine. BMC Complement Altern Med. 2016;16(1):1-12.

18. Ali-Shtayeh MS, Yaniv Z, Mahajna J. Ethnobotanical survey in the Palestinian area: a classification of the healing potential of medicinal plants. J Ethnopharmacol. 2000;73(1):221-32. 
19. Benítez G, González-Tejero M, Molero-Mesa J. Pharmaceutical ethnobotany in the western part of Granada province (southern Spain) Ethnopharmacological synthesis. J Ethnopharmacol. 2010;129(1):87-105.

20. Passalacqua N, Guarrera P, De Fine G. Contribution to the knowledge of the folk plant medicine in Calabria region (Southern Italy). Fitoterapia. 2007;78(1):52-68.

21. Palmese MT, Manganelli REU, Tomei PE. An ethno-pharmacobotanical survey in the Sarrabus district (South-East Sardinia). Fitoterapia. 2001;72(6):619-43.

22. Oran S, Al-Eisawi D. Ethnobotanical survey of the medicinal plants in the central mountains (North-South) in Jordan. J Biodivers Environ Sci. 2015;6(30):381-400.

23. Dorling K. RHS AZ Encyclopedia of garden plants. London: The Royal Horticultural Society; 2008.

24. de Paiva SR, Figueiredo MR, Kaplan MAC. Isolation of secondary metabolites from roots of Plumbago auriculata Lam. by countercurrent chromatography. Phytochem Anal. 2005;16(4):278-81.

25. Motsei M, Lindsey K, Van Staden J, Jäger A. Screening of traditionally used South African plants for antifungal activity against Candida albicans. J Ethnopharmacol. 2003;86(2):235-41.

26. De Paiva SR, De AFontoura L, Figueiredo MR, Mazzei JL, Kaplan MAC. Perfil cromatográfico de duas espécies de Plumbaginaceae: Plumbago scandens L. e Plumbago auriculata Lam. Química Nova. 2002;25(5):717-21.

27. Sharma P, Mujundar A. Traditional knowledge on plants from Toranmal Plateau of Maharastra. Indian J Tradit Knowl. 2003;2:292-6.

28. Jaradat N, Eid A, Abdelwahab F, Isa L, Abdulrahman A, Abualhasan M, et al. Phytochemical analysis, quantitative estimations of total phenols and free radical scavenging activity of Bupleurum subovatum from Jerusalem. Pharm Sci. 2015;21(4):205-10.

29. Trease G, Evans W. A textbook of Pharmacognosy, London. BailliareTindall. 1983;12(193):336

30. Harborne A. Phytochemical methods a guide to modern techniques of plant analysis. Berlin: Springer Science \& Business Media; 1998.

31. Wong C-C, Li H-B, Cheng K-W, Chen F. A systematic survey of antioxidant activity of 30 Chinese medicinal plants using the ferric reducing antioxidant power assay. Food Chem. 2006;97(4):705-11.

32. Jaradat NA, Damiri B, Abualhasan MN. Antioxidant evaluation for Urtica urens, Rumex cyprius and Borago officinalis edible wild plants in Palestine. Pakistan J Pharm Sci. 2016;29(1):325-30.

33. Zheng C-D, Duan Y-Q, Gao J-M, Ruan Z-G. Screening for anti-lipase properties of 37 traditional Chinese medicinal herbs. J Chin Med Assoc. 2010;73(6):319-24.

34. Bustanji Y, Issa A, Mohammad M, Hudaib M, Tawah K, Alkhatib H, et al. Inhibition of hormone sensitive lipase and pancreatic lipase by Rosmarinus officinalis extract and selected phenolic constituents. J Med Plants Res. 2010:4(21):2235-42.

35. Drent M, Larsson I, William-Olsson T, Quaade F, Czubayko F, Von Bergmann K, et al. Orlistat (Ro 18-0647), a lipase inhibitor, in the treatment of human obesity: a multiple dose study. Int J Obes Relat Metab Disord. 1995;19(4):221-6.

36. Sun B, Ricardo-da-Silva JM, Spranger I. Critical factors of vanillin assay for catechins and proanthocyanidins. J Agric Food Chem. 1998:46(10):4267-74.
37. Waterhouse AL. Determination of total phenolics. New York: Wiley; 2002.

38. Jaradat N, Hussen F, Al Ali A. Preliminary phytochemical screening, quantitative estimation of total flavonoids, total phenols and antioxidant activity of Ephedra alata Decne. J Mater Environ Sci. 2015;6(6):1771-8.

39. Pan S-Y, Litscher G, Gao S-H, Zhou S-F, Yu Z-L, Chen H-Q, et al. Historical perspective of traditional indigenous medical practices: the current renaissance and conservation of herbal resources. Evid Based Complement Altern Med. 2014;2014:1-20.

40. Aguiar JJ, Sousa CP, Araruna MK, Silva MK, Portelo AC, Lopes JC, et al. Antibacterial and modifying-antibiotic activities of the essential oils of Ocimum gratissimum L. and Plectranthus amboinicus L. Eur J Integr Med. 2015;7(2):151-6.

41. Martin K, Appel C. Polyphenols as dietary supplements: a double-edged sword. Nutr Diet Suppl. 2010;2:1-12

42. Mulvihill EE, Assini JM, Sutherland BG, DiMattia AS, Khami M, Koppes JB, et al. Naringenin decreases progression of atherosclerosis by improving dyslipidemia in high-fat-fed low-density lipoprotein receptor-null mice. Arterioscler Thromb Vasc Biol. 2010;30(4):742-8.

43. Ado MA, Abas F, Mohammed AS, Ghazali HM. Anti-and pro-lipase activity of selected medicinal, herbal and aquatic plants, and structure elucidation of an anti-lipase compound. Molecules. 2013;18(12):14651-69.

44. Dzomba P, Musekiwa C. Anti-obesity and antioxidant activity of dietary flavonoids from Dioscorea steriscus tubers. JCLM. 2014;2:465-70.

45. Kim S, Kim Y, Hong M, Rhee H. Studies on the inhibitory effect of Eugenia aromaticum extract on pancreatic lipase. Agric Chem Biotechnol. 2005;48(2):84-93.

46. Stahl W. Prevention of age-related diseases: effects of antioxidant supplements. Studies on experimental toxicology and pharmacology. Berlin: Springer; 2015. p. 397-412.

47. Martín MA, Goya L, Ramos S. Preventive effects of cocoa and cocoa antioxidants in colon cancer. Diseases. 2016;4(1):6-20.

48. Amoo SO, Aremu AO, Moyo M, Van Staden J. Antioxidant and acetylcholinesterase-inhibitory properties of long-term stored medicinal plants. BMC Complement Altern Med. 2012;12(1):1.

49. Bircan B, Kirbag S. Plumbago europaea L.'nın besinsel, antioksidan ve antimikrobiyal aktivitesinin belirlenmesi. J Forest Fac. 2015;16(1):30-6.

50. Sini K, Sinha B, Karpagavalli M. Determining the antioxidant activity of certain medicinal plants of Attapady (Palakkad), India using DPPH assay. Current Bot. 2011;1(1):13-6.

51. AlBlooshi A, Shaban S, AlTunaiji M, Fares N, AlShehhi L, AlShehhi H, et al. Increasing obesity rates in school children in United Arab Emirates. Obes Sci Pract. 2016;2(2):196-202.

52. Molarius A, Lindén-Boström M, Granström F, Karlsson J. Obesity continues to increase in the majority of the population in mid-Sweden-a 12-year follow-up. Eur J Public Health. 2016. doi:10.1093/eurpub/ckw042.

53. Zhang J, Xiao L, Yang Y, Wang Z, Li G. Lignin binding to pancreatic lipase and its influence on enzymatic activity. Food Chem. 2014;149:99-106.

54. Bustanji Y, Mohammad M, Hudaib M, Tawaha K, Al-Masri IM, AlKhatib $\mathrm{HS}$, et al. Screening of some medicinal plants for their pancreatic lipase inhibitory potential. Jordan J Pharm Sci. 2011;4(2):81-8. 